\title{
From Failure to Consummation: Students' Perception of Completing Matriculation Exams in Preparation for University Admission
}

\author{
Sara Zamir ${ }^{1,2} \&$ Shiran Avraham ${ }^{1}$ \\ ${ }^{1}$ School of Education, Ben-Gurion University, Eilat, Israel \\ ${ }^{2}$ School of advanced studies, Givat Washington \& Achva Academic Colleges, Israel \\ Correspondence: Prof. Sara Zamir, School of Education, Ben-Gurion University, Eilat, Israel. E-mail: \\ sarahz@bgu.ac.il
}

Received: June 19, 2019

Accepted: July 10, 2019 Online Published: July 26, 2019

doi:10.5539/jel.v8n5p21

URL: https://doi.org/10.5539/jel.v8n5p21

\begin{abstract}
The Israeli pre-academic preparatory programs were initiated in 1963 in order to ensure enhanced accessibility to higher education for diversified populations. Most of the students enroll in the programs after repeated failures at high school. Some manage to break away from the vicious cycle of failures, while others lag behind.

This study investigated the students' perception of their decision to join the programs and complete their final matriculation exams.

The findings illustrated that most of the students had described the post high school completion of the matriculation exams as an ambivalent process which embodied both difficulties and satisfaction. The way these students explained their failure at high school leaded to extensive insights about the learning functioning they acquired during the program and their expectations of success.
\end{abstract}

Keywords: matriculation exams, pre-academic preparatory programs, motivation for learning, failure and success, coping strategies

\section{Introduction}

\subsection{Failure and Success}

Failure and success in psychology studies have preoccupied researchers and theoreticians throughout the years. The literature dealing with these fields have focused on different and varied issues, engaging mostly with mutual impacts between learners' emotional functioning and self-perception and their academic attainments. The theoretical literature which discusses learning processes at school has been very rich; Conversely, reference to studies in programs up to now has been poor and relatively limited, resulting in the actual need for enhancing this topic.

\subsection{Profile of Students Failing at High School}

The theoretical literature advocates that failure at school is usually common to students at risk (Friedman \& Weisman, 1981; Mor, 2006). There are numerous factors which might put students' regular development at risk and their ability to exhaust their skills. Among them: Personal factors-lack of emotional stability, developmental problems, learning disabilities, difficulties in establishing social relationships. Familial factors - poverty, parental dysfunction, parents' emotional problems, more children than the parents can control. Communal factors - lack of a sense of belonging (due to physical body build, accent of speech, way of dressing, not up-to-date in studies, lack of friends, etc.), absenteeism and frequently being late to school, non-participation in extra-curricular activities, use of drugs, alienation of school or the community towards the student and so on (Friedman \& Weisman, 1981; Mor, 2006).

All students carry in their heart their subjective failure. When students experience recurrent failures, they strengthen the equation "I=failure" convincing themselves that they are really a failure (Mor, 2006). Studies illustrate that failing students are generally characterized by low self-image, lack of self-confidence, negative academic self-efficacy (Bandura, 1997); low motivation (Kaplan \& Assor) and lack of involvement in studies (Hadar-Peker, 2013). With time, social, psychological and cognitive residues are formed among students who experience failure in studies. They develop a sense of inferiority and vulnerability which impact all their areas of 
life (Mor, 2006). They are usually characterized by a sense of alienation towards school, negative feelings such as anxiety, anger, jealousy and boredom, behavioral and social problems (Cohen-Navot, Alenbog-Frankovitch, \& Reinfeld, 2001).Two ways of coping with failure are discussed in the literature: positive coping strategies focus on finding a quick and effective solution to problems and negative coping strategies focus on feelings such as lack of trust and threat on one's self (Lazarus \& Folkman, 1984, Mantzicopoulos, 1997). Cohen and Givon (2009) conducted a study which examined the way learners with learning difficulties coped emotionally and cognitively with academic assignments and matriculation exams. The study found two main strategies of coping. One was an adjusting strategy oriented at coping with the learning-cognitive difficulty, aiming to overcome the helplessness and lack of mastery of the learning. The second was a non-adjusting strategy oriented at coping with the negative emotions accompanying the difficulty.

What brings students to choose a particular strategy? The literature indicates a variety of personality-oriented, emotional and social factors associated with students' academic functioning and their ability to handle stressful situations (Hadar-Peker, 2013). Studies attest that motivation is one of the key factors which affect learning attainments (Deci et al., 1991; Dornyei, 2001; Dweck, 2002; Kaplan \& Assor, 2001; Pintrich \& Schunk, 2002). Extensive reference was attributed to motivation in research and in the world of education. This was due to both its contribution to attainments and to its being an educational value.

\subsection{The Motivational Factor for Learning}

Motivation is a multi-faceted structure (Hadar-Peker, 2013), having different components and different definitions. The word "motivation" is derived from the Latin root motivus which means a driving force. One of the prevalent definitions in the literature was conceived by Maehr (1984) who defined three dimensions of motivational behavior. The first is direction-relating to people's choice when implementing one activity rather than the other for persevering in a certain activity even when difficulties are encountered. It also refers to people's wish to continue with the same activity even when they are not required to do it. The second is power - relating to the high or low level of efforts people invest in the activity. The third is quality-relating to people's level of involvement in the assignment. For example, do learners perform the learning assignment well out of deep cognitive involvement or work superficially in order to reach the finish line (Kaplan \& Assor, 2001). Motivation is a central concept in learning since is entails human behavior which involves exerting great efforts (Dornyei, 2001).

Numerous researchers and theoreticians tend to distinguish between two types of motivation for learning. Intrinsic regulation [motivation] which describes a situation whereby people perform an activity out of pleasure, inquisitiveness and mastery of the material. They invest efforts and time since the activity reflects their tendencies and areas of interest rather than acting due to external pressure or wish for some reward. Conversely, there is extrinsic regulation [motivation] which considers engagement in a specific activity as a means for accomplishing another goal (Assor, 2001; Deci et al., 1991; Hadar-Peker, 2013; Pintrich \& Schunk, 2002). Extrinsic motivation might exist on different levels of introversion: on the highest extrinsic level-people perform patterns of behavior in order to get a promised prize or to avoid a threatened punishment which threatens them; on the less extrinsic level-people perform patterns of behavior in order to fulfil expectations of other people who are important to them. This type of motivation is also referred to as desirability; on the highest introversion level - people perform patterns of behavior since they identify with the value of the behavior. People may think that a certain behavior is important or value-oriented although it is not pleasurable or interesting. This type of motivation is also referred to as cognitive motivation (Deci et al., 2001; Kaplan, 2014; Kaplan \& Assor, 2001). The self-determination theory presents the intrinsic and extrinsic regulation not as a dichotomy but as two extremes of a continuum. The more intrinsic the perceived motives are, stemming from people's need for autonomy, ability as well as contact and sense of belonging, the higher the quality of the motivation (Deci et al., 1991).

The Causal Attribution Theory (Weiner, 1986) discusses three main dimensions of the perceived causes of success and failure. The locus dimension-is the external or internal cause; the control dimension - is the cause perceived as controllable or uncontrollable; and the stability dimension-is the cause perceived as permanent and continuous characteristic or as changing and transient. Integration of the three dimensions develops students' expectations and emotions which affect their motivation to invest and try succeeding in future (Hadar-Peker, 2013; Peterson \& Barrett, 1987; Weiner, 1986). This theoretical framework defines several classic causes which students use for explaining successes and failures in studies, e.g. effort, capability, luck and the assignment's level of difficulty (Weiner, 1986). The locus of the cause entails various emotions associated with the responsibility students perceive as success or failure. One of the options available to students who failed their 
matriculation exams at high school is the programs designed to offer weak groups a second opportunity for completing and improving their matriculation certificate (Hayush \& Fresko, 2006).

\subsection{Characteristics of the Academic Preparatory Programs}

Organizing the programs in Israel started in 1963 aiming to make higher education accessible to a population defined as "worthy of promotion" from learning and social aspects (Arieli, 1997). The programs are divided into three types: matriculation-oriented preparatory courses; specific faculty-designated programs; and programs for special population (Ariav \& Haim, 2010). Every program is designed to enable students with low basic personal data to be dissociated from their failure-filled past and overcome the hurdles which determine their chances of admittance to higher education institutions (Arieli, 1997; Talmor \& Kayam, 2006). The matriculation-oriented program constitutes a tool which provides young people without a complete matriculation certificate or those who obtained grades which are too low, a second opportunity to complete and improve their attainments so that they can enroll in higher education institutions. The policy of the second opportunity system is grounded in the fundamental assumption that there is a significant relation between education and ability to earn money and find work (Ariav \& Haim). Hence, this system is designed to bridge educational gaps, moderate inequality and stimulate social mobility by presenting alternate ways of acquiring education (Hayush \& Fresko, 2006). Researchers who investigated the alternate ways in Israel doubt their ability to actualize what is expected of them and promote in practice the target population (Ayalon, Shavit \& Shapira, 1992). Nevertheless, researchers indicate the programs as a successful alternative and point out high learning successes of program students [hereafter-“"students"] (Arieli, 1997; Ayalon et al., 1992).

One of the differences between high school students and program students is age. During high school students undergo physiological and hormonal changes typical of adolescence years (12-18). They consolidate their identity and are characterized by sharp mood fluctuations and wish to achieve a high social status (Adar, 2002; Givon \& Cohen, 2009; Polak, 2011). On the other hand, the age at young adulthood years (18-30) is typical of the students. It constitutes a main junction of anything related to personal decisions which have vast implications for the future of young people in almost all their areas of life, among them higher education, employment, housing, inter-personal relationships and so on (Zeira, 2012). As mentioned, this stage has not been sufficiently researched as far as the process of post high school matriculation completion is concerned. Consequently, the present study strives to expand on the existing knowledge in this field and thoroughly explore this issue.

Research aim: Exploring students' perceptions of the post high school "MCP", starting from the decision-making stage, through motives and perceived cause of failure at high school and up to coping with the sense of failure, expectations and apprehensions brought about by this process.

Research questions: How do students make the decision to complete their matriculation exams? What are the preferred motives for learning in a program rather than in other alternatives? What are the perceived causes of failure at high school? How do students cope with this failure? What are the expectations from and apprehensions towards the matriculation completion process [hereafter- "MCP"] and in general what does the personal experience of learning in a program embody - feelings, emotions, motivation and difficulties experienced throughout the process?

\section{Method}

This study was conducted by the qualitative research approach which aspires to comprehend the world as it is perceived by the research participants (Sabar Ben \& Yehoshua, 2001). The rationale underlying the choice of this methodology is based on the fundamental assumption according to which qualitative research can identify subtle details and find the deep dimensions of the "MCP" as it is perceived by the students from their own subjective perspective.

\subsection{Research Tools}

The research data was collected by using an open-ended structured questionnaire and content analysis of the participants' responses. In the first part of the questionnaire the students were asked to specify general details about their age, gender, state of their matriculation exams prior to the program and the state of their matriculation exams at present. The second part of the questionnaire comprised seven open-ended questions about the students' personal perceptions of the "MCP": decision, motives, causes for failure at high school and coping with it, expectations, apprehensions and overall experience. The students' answers were analyzed by a combined content analysis which included both a quantitative aspect (frequencies and volume of the participants' responses) and a qualitative aspect (detailed citations and verbal content interpretation). The high validity of the 
research tool stems both from the profound theoretical background upon which it was based and the very triangulation it embeds.

\subsection{Research Population}

The research population comprised of 59 students aged 20-25 learning in a matriculation-oriented programs in a southern city of the country ( 31 females and 28 males). Most of the research participants ( 36 students $=61 \%$ ) joined the program with a partial matriculation.

\section{Results}

Most of the data collected throughout the study was presented by distribution into seven main categories. Each category was divided into sub-categories according to the students' responses. The summing up of each category was presented in a table. Frequency of student participant responses are indicated in the left column and representative examples of selected citations demonstrating ideas are presented in the right column. In order to enhance the findings, only the first assertion of each student was taken into consideration, assuming this was the most representative assertion.

Table 1. Making a decision to complete matriculation exams

\begin{tabular}{|c|c|}
\hline Category No. 1-Making a decision & omplete matriculation exams (Note 1) \\
\hline $\begin{array}{l}\text { Aspiration to be admitted to higher } \\
\text { education (32) }\end{array}$ & $\begin{array}{l}\text { "I knew that in order to graduate with a degree I must first complete all the matriculation exams } \\
\text { in which I failed". }\end{array}$ \\
\hline & "The admittance prerequisites compelled me to improve my matriculation certificate". \\
\hline Wish to develop: be employed in a & "I felt that I was stuck at a workplace which offered nothing useful". \\
\hline $\begin{array}{l}\text { good place of work and earn money } \\
\text { (13) }\end{array}$ & $\begin{array}{l}\text { "In order to provide for a family, I needed a permanent job and thus I could somewhat alleviate } \\
\text { the worries of livelihood". }\end{array}$ \\
\hline Something which is self-obvious (6) & $\begin{array}{l}\text { "It was obvious that sooner or later I would do it, I simply waited for the right time when I was } \\
\text { free". }\end{array}$ \\
\hline & $\begin{array}{l}\text { "It was something I knew I would do immediately after being discharged from the military } \\
\text { service ". }\end{array}$ \\
\hline Maturity: understanding the & "The person I was at high school is not the person I am today". \\
\hline importance of studies (5) & $\begin{array}{l}\text { "Today I am more mature... understand this is not a game and this is real life. In order to succeed } \\
\text { I have to invest in studies". }\end{array}$ \\
\hline
\end{tabular}

Table 2. Motives for preferring to learn in the matriculation-oriented preparatory program rather than in other alternatives

$\begin{aligned} & \text { Category No. 2-Motives for preferring to learn in the matriculation-oriented preparatory program rather than in other } \\ & \text { alternatives (Note 2) }\end{aligned}$
$\begin{array}{ll}\text { Need for a learning framework (8) } & \text { "The program helps organizing the time, puts you in a framework". } \\ & \text { "It is better than high school because here the learning is exam-oriented ... I myself have no } \\ \text { self-discipline and I need a framework". } & \text { "I consulted a family member and he recommended the program to me". } \\ \text { "I came here following a recommendation of a colleague who had done the same learning path". } & \text { "Wish for breaking the routine, new environment, meeting people and friends as well as thinking } \\ \text { (7) } & \text { about the future". } \\ \text { Need for a social framework (4) } & \text { situation as you". } \\ & \text { "The programs offer many benefits and assistance to lone soldier". } \\ \text { "I heard that there was an option to receive scholarships; it helps a lot during the studies period". } \\ \text { "Matriculation certificate is valid for all places". }\end{array}$
$\begin{aligned} & \text { Matriculation certificate which is } \\ & \text { valid for all high education } \\ & \text { institutions (1) }\end{aligned}$


Table 3. Perceived causes of failure at high school

\begin{tabular}{ll}
\hline Category No. 3-Perceived causes of failure at high school \\
\hline Lack of motivation (27) & "I simply did not invest enough... I had no goals which required me to take the matriculation exams". \\
"I was actually a very lazy boy and had no wish to study. My head was in other places". & "I made efforts but to no avail". \\
Difficulties in studies (10) & "Lack of comprehension and many difficulties in a certain subject made me "throw in the towel"”. \\
"I had learning difficulties which have not been properly diagnosed at school". & "I could not attend school in the last two years because I had to undergo an operation and long \\
Medical, economic and familiar & rehabilitation period". \\
causes (8) & $\begin{array}{l}\text { "I dropped out of school in the 10th grade as I had to work and help provide for the family". } \\
\text { "My family changed its place of residence in midlife and I had to go to a new school where I knew no } \\
\text { one. It was horrible". } \\
\text { "Every day I went to the beach, surfed, met friends, girls, new experiences. Who ever thought about } \\
\text { studying?" } \\
\text { "I was influenced by new friends and they took me towards rather bad directions". } \\
\text { "I think that I took adolescence rebellion a "step forward' and even annoyed my parents..." } \\
\text { "Before each test I did not sleep at night and I woke up in the morning feeling sick only because of the } \\
\text { stress". } \\
\text { "I felt that if I did not succeed in the matriculation exams I would fail in life and this made me } \\
\text { extremely stressed". }\end{array}$ \\
\hline
\end{tabular}

Table 4. Coping with the experience of failure at high school

\begin{tabular}{|c|c|}
\hline \multicolumn{2}{|c|}{ Category No. 4-Coping with the experience of failure at high school } \\
\hline Indifference (27) & $\begin{array}{l}\text { "It did not bother me at all, at that time it did not interest me". } \\
\text { "I was 'cool' about it... I did not invest in school". }\end{array}$ \\
\hline Avoidance and remorse (13 & $\begin{array}{l}\text { "I repressed the failure for years until I decided to cope with the difficulty. I realized that I had made a } \\
\text { serious mistake at high school". } \\
\text { "I did not cope, I ran from it. I opened my eyes too late and I have to deal with it now and it is not easy } \\
\text { at all". } \\
\ldots \ldots \ldots \ldots \ldots \ldots \ldots \ldots \ldots \ldots \ldots \ldots \ldots \ldots \ldots \ldots \ldots \ldots \ldots \ldots \ldots \\
\text { "I always felt uneasy about not studying enough and it was a shame I was not investing more. Today I } \\
\text { am paying the price". }\end{array}$ \\
\hline $\begin{array}{l}\text { Sense of injustice and missing } \\
\text { an opportunity (6) }\end{array}$ & $\begin{array}{l}\text { "No sense of failure but rather a rational sense of injustice because I invested a lot in my studies being a } \\
\text { diligent learner". } \\
\text { "The matriculation grades disappointed me because I attended all the lessons and studied for the } \\
\text { exams". }\end{array}$ \\
\hline Optimism (6) & $\begin{array}{l}\text { "It's not the end of the world... I took it in proportion and knew I would complete it sometime". } \\
\text { "You don't look backwards... everything is going to be all right". }\end{array}$ \\
\hline I did not fail (7) & $\begin{array}{l}\text { "I graduated high school with a full matriculation certificate. I have joined the program only for } \\
\text { improving my grades". }\end{array}$ \\
\hline
\end{tabular}

Table 5. Expectations from the matriculation completion process

\begin{tabular}{|c|c|}
\hline \multicolumn{2}{|c|}{ Category No. 5-Expectations from the matriculation completion process } \\
\hline Succeed and attain good grades & "I expect to get grades which reflect my real capabilities". \\
\hline (28) & "I want to get good grades in order to meet the university admittance prerequisites". \\
\hline $\begin{array}{l}\text { Pass the exams and graduate } \\
\text { (26) }\end{array}$ & $\begin{array}{l}\text { "That I pass all the matriculation exams the first time. I don't care if I score } 55 \text { in all the exams. The } \\
\text { main thing is that the exams are over and I can advance in life". }\end{array}$ \\
\hline & "I simply want to complete the matriculation exams and move on to the next stage". \\
\hline $\begin{array}{l}\text { Acquire knowledge and } \\
\text { competences (5) }\end{array}$ & $\begin{array}{l}\text { "Improve my self-discipline. Learn how to learn and most importantly acquire knowledge and } \\
\text { education". }\end{array}$ \\
\hline & $\begin{array}{l}\text { "I expect to get all the tools and learning knowledge for succeeding in both the matriculation exams and } \\
\text { in future". }\end{array}$ \\
\hline
\end{tabular}


Table 6. Apprehensions about the matriculation completion process

\begin{tabular}{|c|c|}
\hline \multicolumn{2}{|c|}{ Category No. 6-Apprehensions about the matriculation completion process } \\
\hline Experience another failure (37) & $\begin{array}{l}\text { "My deepest apprehension is that God forbid I will not pass the matriculation exams and that all this } \\
\text { was in vain". } \\
\text { "I am going to miss it. I have got a second opportunity and do not invest the best of me". } \\
\text { "Today the studies do interest me, so that if I fail, I would feel a sense of failure and great } \\
\text { disappointment". }\end{array}$ \\
\hline $\begin{array}{l}\text { Not accomplish the targets I } \\
\text { have set for myself (13) }\end{array}$ & $\begin{array}{l}\text { "I am worried that I won't get sufficiently high grades because I have to work many hours and this does } \\
\text { not allow me to invest in the studies". } \\
\text { "My main apprehension is getting grades which do not reflect my real capabilities and not } \\
\text { accomplishing the targets I have set for myself". }\end{array}$ \\
\hline No apprehensions (9) & $\begin{array}{l}\text { "I don't have even one apprehension, none. You learn, succeed, period". } \\
\text { "To tell the truth, I don't have so many apprehensions, I am quite confident of myself". }\end{array}$ \\
\hline
\end{tabular}

Table 7. Personal experience of the studies in the preparatory program

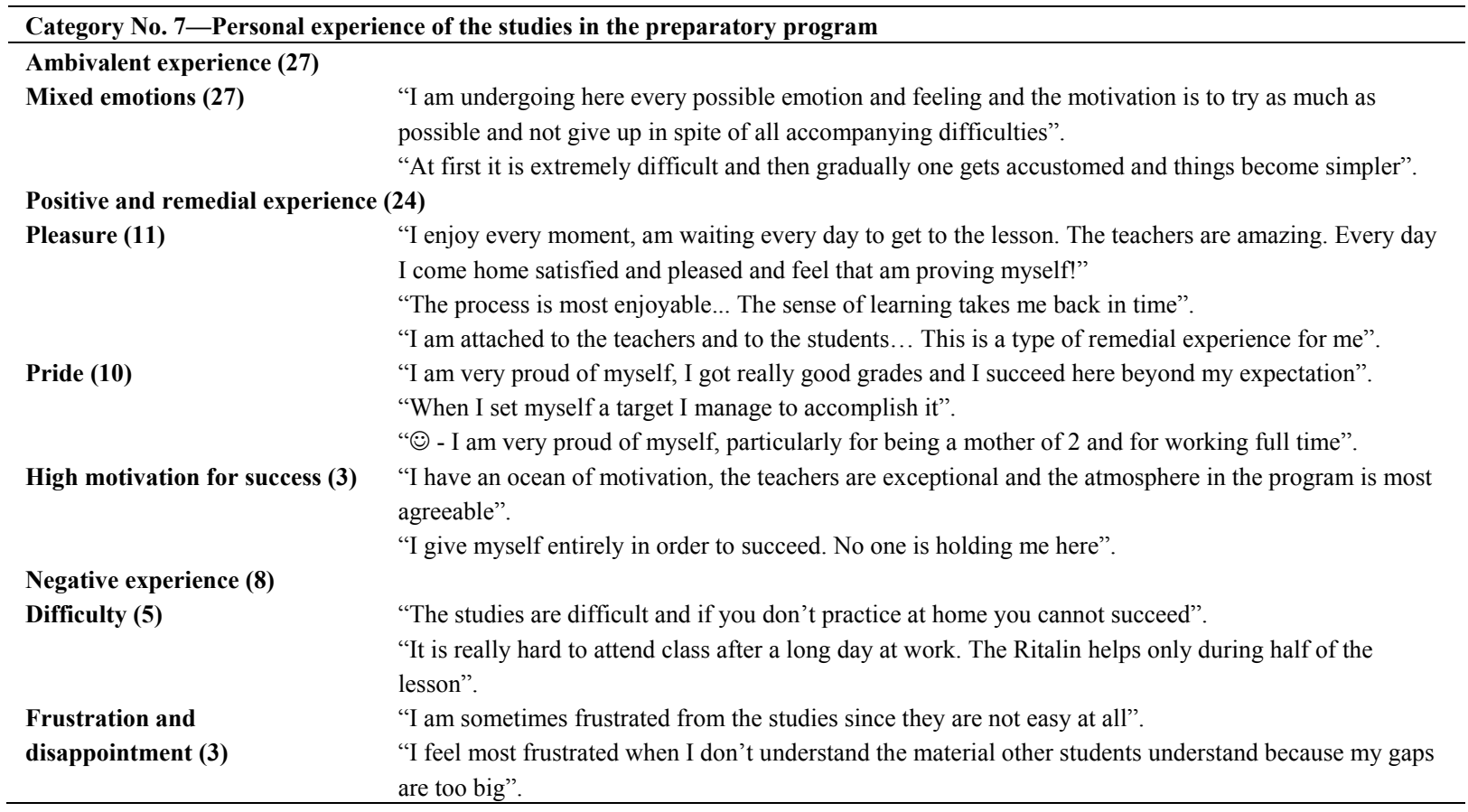

The main findings presented above attest that the students perceive the "MCP" in different and varied ways. The most salient finding that characterizes the majority of the students is related to their aspiration to be admitted to academic studies, to their need for learning and social framework; their awareness of the lack of motivation which caused their failure at high school; the indifference resulting from the failure and their lack of investment; their expectations to successfully graduate the program; and their apprehension of experiencing another failure. It seems that eventually this concerns an ambivalent experience which embodies numerous difficulties and frustration but also a source of pride, satisfaction and pleasure.

\section{Discussion \& Conclusions}

The findings show that students' main and most salient cause for making the matriculation completion decision is the aspiration to start their academic studies. Moreover, they realized that the admittance to first degree studies in most higher education institutions requires a full matriculaation certificate. Apparently, students who experienced failure at high school join the program, among others, with the purpose of proving to themselves and their environment that they are capable of coping with the challenge of studies and of being admitted to the academia.

Moreover, the decision to complete their matriculation stems from additional reasons. The feeling of being 'stuck' and not advancing stimulates the students to do something in order to change the situation. Most students work on a daily basis with minimal salary. Only at the stage whereby they feel they have exhausted their potential and wish to be promoted to more senior positions, they start seeing higher education as an option. 
Many studies illustrate a significant relation between education and income and employment (Ariav \& Haim, 2010; Frisch, 2007; Taub Center, 2014). The students who decided to complete their matriculation exams due to their wish to be hired for profitable work and earn more money, are mainly driven by extrinsic motivation (Assor, 2001; Deci et al., 1991; Hadar-Peker, 2013; Pintrich \& Schunk, 2002). This implies that most students perceive the matriculation completion not as a target by itself but rather as a means for accomplishing another goal. They decide to invest in studies wishing to receive a lucrative external reward, i.e. high wages, good job, prestigious social status or attempting to avoid being 'punished', for example by remaining in a low socioeconomic class.

Nevertheless, some students believed that completing the matriculation was a normative social step for developing self-efficacy (Bandura, 1997) and expelling feelings of inferiority (Mor, 2006). Another aspect of the same matter is the wish to align themselves with the expectations and demands of their environment either out of desirability motivation (Deci et al., 1991; Kaplan, 2014; Kaplan \& Assor, 2001) or giving in to social pressure (Bernheim, 1994). Another cause expressed by several students was the delayed acknowledgement of the importance of studies. It seems that these students were motivated to study by conscious motivation (Deci et al., 1991; Kaplan, 2014; Kaplan \& Assor, 2001). That is, high internalization of the value of studies and not necessarily the perception that matriculation completion can be an enjoyable or interesting activity. The students argue that this decision stems from the adolescence and maturity process, leading them to identify the relation between investment and success (Talmor \& Kayam, 2006).

Category No. 2 relates to the motives for preferring to learn in the matriculation-oriented preparatory program rather than in other alternatives. Most of the findings regarding this category illustrated that one of the main motives is students' need for a learning framework. Most of them referred to the difficulty of studying alone. One can assume that possible accomplishments of the very population depends upon the assistance as well as professional direction granted by the program (Arieli, 1997; Talmor \& Kayam, 2006). Those students perceived the program as a framework which could provide for the need of belongingness. According to the self-determination theory (Deci et al., 1991), these factors enhance the students' motivation as well as involvement in the "MCP".

Surprisingly enough, scholarships were not found as a major motive for learning in the program contrary to evidences that the population of the programs comes from a difficult socio-economic background (Arieli, 1997; Ayalon et al., 1992; Hayush \& Fresko, 2006). Perhaps the students believe the scholarships they are granted are recognition of the economic burden imposed by full tuition fees, rather than as a bonus.

Category No. 3 presents the students' perceived causes of failure at high school. The meanings and implications of the findings in this category are extremely crucial. The empirical literature advocates that the causes people attribute to their successes and failure attest to their motivation and determination to invest and try succeeding in similar situations in future.

Most of the students' answers accounted for the failure they experienced at high school. One obvious explanation resides in physiological and psychological changes (Adad, 2002; Givon \& Cohen, 2009; Polak, 2011) which make adolescents wish to have new experiences mainly with the peer group instead of investing in studies towards the matriculation exams. The answers of the students who explained that the failure at high school stemmed from youthful folly imply that at higher ages they were capable of changing and succeeding.

Conversely, many students explained their failure at high school as a result of learning difficulties. These students seem to have invested in studies, yet they failed. In this case the students attributed their failure mainly to their limited cognitive ability. Although low cognitive ability is a classic explanation of success and failure in studies (Dweck, 2002; Weiner, 1986), now it seems the students perceive themselves as having learning efficacy. We can assume that students who decided to attend the program would not have done it if they had not believed a second opportunity might change things and grant them a remedial experience after the failure.

Some students pointed out that external factors, such as medical, economic or familial situation account for their failure. It is reasonable to assume that students with Resiliency (Werner, 1989), high academic efficacy, intrinsic motivation (Deci et al., 1991) and developed cognitive capability (Hadar-Peker, 2013; Kaplan \& Assor, 2001) will overcome external traumatic factors and will tend to succeed.

A few students indicated that the cause of their failure at high school was stress and test anxiety. These feelings evoke despair and inability to study which eventually cause a recurrent failure (Ben-Lavi, Turel, Gumpel, Pinus, Vinokor, \& Schneiderman, 1995). One can only posit that if the test anxiety of those students has not yet been addressed, they would experience self-fulfilling prophecy and additional failures. 
There are tangent lines between the perceived causes of failure at high school and the ways of coping with it. Findings of Category No. 4 illustrate that students who did not exert any efforts at high school were indifferent to the failure whereas students who invested in studies experienced the failure to greater extent. These findings are compatible with previous studies (Givon \& Cohen, 2009; Lazarus \& Folkman, 1984; Mantzicopoulos, 1997) that draw a direct line between personal investment and caring.

The students' strategies of coping with failure at high school can be accounted for by the attribute style (Weiner, 1986) and locus of control (Rotter, 1966). That is, students with an intrinsic locus of control who were optimistic towards the failure and attributed it to controllable and transitory causes coped better with past failure. Conversely, in the case of students who attributed failure at high school to extrinsic uncontrollable and permanent causes, failure evoked negative emotions and tendency to stagnation.

Category No. 5 presents the expectation of students from the matriculation completion process, divided into three group. The first group to which most of the students belong related to those who joined the program with great ambitions and wish to succeed. The second group comprised students with low expectations who settled for an average level and were only interested in passing the exams threshold. The third, representing a minority of students, described those who expected to undergo a process of deep approach to learning, providing them with effective learning competences and strategies which will serve them in future. The nature of the students' expectations from the "MCP" can illustrate a lot about the intensity of their motivation. Students aspiring to attain high grades will be characterized by a higher investment level than students who settle for a "pass" grade. Similarly, students interested in acquiring knowledge and competences throughout the process will demonstrate a more meaningful cognitive involvement than students who perform learning activities in a superficial manner in order to meet the minimum requirements (Kaplan \& Assor, 2001; Maehr, 1984).

Findings of Category No. 6 clearly show that the apprehension of re-living the failure at high school (37) is dominant and is stronger than the apprehension of failing to meet the goals students had set for themselves (13). Since the program constitutes a second opportunity for the students, they feel a stronger fear of repeating past mistakes and intensify the experience of failure. In fact, many studies indicate that recurrent failures cause students to feel helpless, strengthen their equation "I = failure" and might convince them they are really a failure (Cohen-Navot et al., 2001; Hadar-Peker, 2013; Kaplan \& Assor, 2001; Mor, 2006).

On the other hand, some students are not apprehensive of the "MCP" (9) and demonstrate high confidence in their ability to succeed in studies. Apparently, the differences between the groups are mainly personality-oriented and it is difficult to predict actual success or failure based on them.

Category No. 7, presents the personal experience of the students. The majority of students described "MCP" as an ambivalent experience which evoked mixed feelings. The findings show that on the one hand they are aware of the difficulties and frustration but on the other they acknowledge the power of the new context. Many students perceived the "MCP" as a remedial experience for failure. They expressed positive feelings such as pleasure, pride satisfaction and sociability. These findings are in line with the factors attributed to students' success in other programs (Talmor \& Kayam, 2006) since they are related to the investment of the students themselves, unique teaching style and supporting environment provided by the program.

Conversely, there was a small group of students (8) whose personal experience of the "MCP" in the program was extremely negative. These students described the difficulty to integrate the learning requirements with their work restraints. They were working long hours in order to provide for themselves and this rendered it difficult to concentrate in the lessons and practice at home. Others were disappointed with themselves as they repeated their same mistake at high school, feeling strong frustration about the learning gaps which have accompanied them until today, in the capacity of a vicious circle. Essential social, psychological and cognitive residues were formed following failure in studies which lasted a long time (Mor 2006). Moreover, a sense of alienation and negative emotions were evoked at the same time (Cohen-Navot et al., 2001).

This study led to several insights. Firstly, it elucidates students' motivation and places it in a new order as an essential component of the "MCP" and the success thereof. Secondly, the research findings indicate the long-term implication of failure at high school. At the same time, they illustrate that the environmental attribution style, locus of control and students' goals to be achieved have a considerable impact on the way they perceive the "MCP" in general. Thirdly, the study shows that the students perceive the program as an academic framework which can address their essential needs such as autonomy and sense of belonging.

Based on the above, a desirable applied conclusion is that programs should attribute weight to the students' needs, from their enrollment in the program until they achieve a full matriculation certificate. The academic support should encompass attention to the students' decision and motives for studying, causes of their failure at 
high school and way of coping as well as their expectations and apprehensions about the "MCP". Thus, we might be able to improve students' motivation, perseverance and considerable involvement in the learning process.

Together with the meaningful contribution, we should point out the research limitation, namely that just one program, due to accessibility and sampling convenience, has been investigated. Below are proposals for further studies which might expand on the existing knowledge in this field. For example, exploring the way students from other Israeli programs perceive the "MCP"; comparing the learning experience in a matriculation-oriented program versus a designated program; conducting a longitudinal study of the success percentage in the first-degree studies of students who have started their way in the program. Furthermore, the use of different and varied research instruments is recommended, both qualitative and quantitative, striving to understand the world as it is perceived by the research participants. On the other hand, split reality into its components, examine relations between variables and perhaps discover some legal aspects. All these could definitely shed light on more interesting issues and constitute a meaningful contribution in both the empirical and practical aspects, to the professional literature which deals with pre-academic preparatory programs in Israel.

\section{References}

Adad, M. (2002). Negativism at adolescence. In M. Adad \& Y. Wolf (Eds.), Delinquency and social deviation: Theory and implementation (pp. 41-50). Ramat Gan: Bar-Ilan University. [Hebrew]

Ames, C. (1992). Classrooms: Goals, structures and student motivation. Journal of Educational Psychology, 84, 261-271. https://doi.org/10.1037/0022-0663.84.3.261

Ariav, Y., \& Haim, O. (2010). The committee for the examination the activity of pre-academic preparatory programs - a summing up report. Jerusalem: Ministry of Education. [Hebrew]

Arieli, M. (1997). Assessment of the contribution of the pre-academic preparatory programs to the higher education system. Findings of a follow-up research in the years 1992 and 1993 (Report No. 240). Jerusalem: National Center for Exams and Assessment. [Hebrew]

Assor, A. (2001). Promotion of intrinsic motivation for learning at school. Education of Thinking, 20, 167-190.

Bandura, A. (1997). Self-efficacy: The exercise of control. New York: Freeman.

Ben-Lavi, S., Turel, M., Gumpel, O., Pinus, A., Vinokor, M., \& Schneiderman, M. (1995). Test exam among adolescents. Tafnit, 8. [Hebrew]

Bernheim, D. B. (1994). A Theory of Conformity. Journal of Political Economy, 102(5), 841-877. https://doi.org/10.1086/261957

Cohen-Navot, M., Alenbog-Frankovitch, S., \& Reinfeld, Y. (2001). The overt and covert dropout among adolescents. Jerusalem: The Israeli Parliament and Joint-Brookdale Institute. [Hebrew]

Deci, E. L., Vallerand, R. J., Pelletier, L. G., \& Ryan, R. M. (1991). Motivation and education: The self-determination perspective. Educational Psychologist, 26, 325-346. https://doi.org/10.1207/s15326985ep2603\&4_6

Dornyel, Z. (2001). Motivation strategies in the language classroom. Cambridge: Cambridge University press. https://doi.org/10.1017/CBO9780511667343

Dweck, C. S. (2002). Messages that motivate: How praise molds students' beliefs, motivation, and performance (in surprising ways). In J. Aronson (Ed.), Improving academic achievement: Impact of psychological factors on education (pp. 37-60). San Diego, CA, US: Academic Press. https://doi.org/10.1016/B978-012064455-1/50006-3

Friedman, R. R., \& Weidman, S. G. (1981). Dropout of school, a conceptual approach to the literature review. Megamot, 2, 174-189. [Hebrew]

Frisch, R. (2007). The output of education-the causal relation between education and wages. Jerusalem: Bank of Israel, Research Department. [Hebrew]

Givon, S., \& Cohen, A. (2009). Cognitive and emotional processes experienced by pupils with learning disability when coping with the achievement of matriculation certificate. Educational Counsellor, 15, 67-99. Jerusalem: Shefi. [Hebrew]

Hadar-Peker, D. (2013). Relation between socio-emotional state and learning attainments of school pupils. Invited review as background material for the work of the committee "Education System to everybody and 
to everyone". Jerusalem: Initiative for applied research in education. [Hebrew]

Hayush, T., \& Fresko, B. (2006). Pre-academic preparatory program in a teacher education college as a second opportunity for weakly-achieving groups. Dapim, 41, 87-108. [Hebrew]

Kaplan, A., \& Assor, A. (2001). Motivation for learning at school-from theory to practice. Education for Thinking, 20, 13-35.

Kaplan, H. (2014). Self-determination and motivation. Lexi-Kay, Kay College Bulletin, 2, 15-17. [Hebrew]

Lazarus, R. S., \& Folkman, S. (1984). Stress, Appraisal, and Coping. New York: Springer.

Maehr, M. L. (1984). Meaning and motivation: Toward a theory of personal investment. In C. Ames \& E. Ames (Eds.), Research on motivation in education, 1, 115-144.

Mantzicopoulos, P. (1997). How do children cope with school failure? A Study of social/emotional factors related to children's coping strategies. Psychology in the schools, 34, 229-237. https://doi.org/10.1002/(SICI)1520-6807(199707)34:3<229::AID-PITS5>3.0.CO;2-J

Ministry of Education (2009). The 4 "M"s. Bulleting for the promotion of leadership, professionalism, professionality and excellence in elementary school management, 25. [Hebrew]

Mor, P. (2006). To see the children: A guidebook for creating a growing educational environment for pupils at risk. Jerusalem: Ashalim. [Hebrew]

Pintrich, P. R., \& Schunk, D. (2002). Motivation in education: Theory, research, and applications (2nd ed.). Upper Saddle, NJ: Prentice-Hall, Inc.

Polak, A. (2011). Characteristics of junior high school and adolescence and their impact on teaching and learning. Jerusalem: Initiative for applied research in education, The Israeli National Academy of Sciences. [Hebrew]

Sabar Ben-Yehoshua, N. (2001). Introduction to the history of qualitative research, impacts and currents. In N. S. Ben-Yehoshua (Ed.), Tradition and currents in qualitative research (pp. 13-28). Lod: Dvir. [Hebrew]

Talmor, R., \& Kayam, A. (2006). To what do students with learning disability in a pre-academic preparatory program attribute their learning successes? Issues in special education and rehabilitation, 21, 45-56. [Hebrew]

Taub Center. (2014). State of the Country Report 2014. Retrieved from http://taubcenter.org.il

Weiner, B. (1986). An attribution theory of motivation and emotion. New York: Springer-Verlag. https://doi.org/10.1007/978-1-4612-4948-1

Werner, E. E. (1989). High-risk children in young adulthood: A Longitudinal study from Birth to 32 Years. American journal of orthopsychiatry, 59, 72-81. https://doi.org/10.1111/j.1939-0025.1989.tb01636.x

Zeira, A. (2012). Vulnerable adolescents during processes of transition to matriculation: needs, services and policy. A summary report. Jerusalem: Hebrew University of Jerusalem. [Hebrew]

\section{Notes}

Note 1. Please note that most of the program students tended to give an answer which included more than one cause for making a decision to complete their matriculation exams. However, in order to maintain $\mathrm{N}=59$ we took into consideration only the first cause written by every student.

Note 2. In this category, the total frequency of all the answers (23) is smaller than the number of participants (N = 59) since some of the students did not respond to the question properly. A possible explanation is that the question seemed too similar to the previous question about the decision to complete the matriculation exams and this probably confused some of the students and made them repeat their answers from Category No 1, or not answer at all.

\section{Copyrights}

Copyright for this article is retained by the author, with first publication rights granted to the journal.

This is an open-access article distributed under the terms and conditions of the Creative Commons Attribution license (http://creativecommons.org/licenses/by/4.0/). 